\title{
Advice for Applying to Dermatology as an Applicant of Color: Keep Going
}

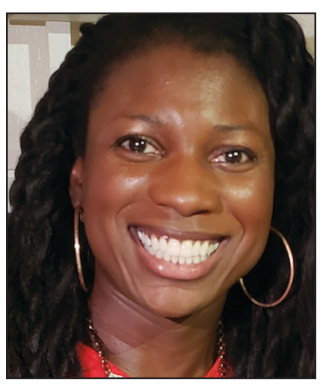

Nicole A. Negbenebor, MD

\section{RESIDENT PEARL}

- Finding a strong mentor who can both advocate for and help guide a student of color through the admissions process is integral to matching into dermatology.
Dermatology is one of the most competitive medical specialties to apply for residency. There is a lack of diversity in dermatology, and the cause is multifactorial. There often are many barriers for students of color gaining acceptance into dermatology. This article explores the personal experience of applying to dermatology as an applicant of color and outlines ways that future students of color can be successful in the match process for dermatology.

Cutis. 2021;107:E15-E16.

A $\mathrm{s}$ the dermatology admissions cycle restarts, I reflect back on my journey as a Black woman applying to dermatology. Before deciding, I internally questioned, "Is dermatology right for me?" There were not many faces that looked like mine within the field. After committing to dermatology, I asked dermatologists - almost any who would spare a few minutes to talk to me-how to get into this specialty and be successful when applying. I spoke to advisors and friends at my home department, emailed dermatologists far and wide, approached conference lecturers after their presentations, sought out advice from current residents, and asked prior applicants what they thought was important to match into dermatology. There had been too many unmatched students before me who had achieved good grades and aced US Medical Licensing Examination Step 1 . The equation for success was missing a variable.

\section{Mentorship}

One weekend, I attended a conference for patients with skin of color. I talked to a student who had taken a year off (retroactively after not matching in prior years). She told me that the biggest key to matching was mentorship; forming a strong relationship with a clinician or investigator who had seen how well you perform in clinic or during research was paramount. Having a collaborator or instructor write you a letter of recommendation and make calls on your behalf could be the difference between matching or taking another year off. More often than any other aspect of the application, it is a lack of mentorship that many students of color do not have access to when pursuing a highly competitive specialty such as dermatology. ${ }^{1,2}$ In such a small field, applicants need someone to vouch for them-to speak on their behalf compassionately, invite them to collaborate on research projects, and inform them of conference opportunities to present their work.

\section{Representation in Dermatology}

We are told that you can accomplish anything with hard work and grit; however, without the platform to show how effectively you have worked, your efforts may never be seen. The diversity statistics for dermatology are clear and disheartening. Although $13 \%$ of Americans are Black, only $3 \%$ of all dermatologists are Black. ${ }^{2,3}$ Just over $4 \%$ of dermatologists are Hispanic compared with $16 \%$ of the

From the Department of Dermatology, Warren Alpert Medical School of Brown University, Providence, Rhode Island.

The author reports no conflict of interest.

Correspondence: Nicole A. Negbenebor, MD (nicole_negbenebor@brown.edu).

doi:10.12788/cutis.0166 
general population. The Association of American Medical Colleges reported that the overall 2015 medical school acceptance rate was $41 \% .{ }^{4}$ White $(44 \%)$, Asian $(42 \%)$, and Hispanic or Latino (42\%) applicants all had similar acceptance rates; however, only one-third of Black applicants were accepted. At graduation in 2015, White individuals were $51 \%$ of matriculants. Medical graduates were only $6 \%$ Black. ${ }^{4}$ What percentage of these $6 \%$ Black graduates thought about applying into dermatology? How many had someone to encourage them to pursue the specialty or a mentor who they could ask about the nuances and strategy to be a competitive applicant?

In addition to discrimination, social psychologists have described stereotype threat, a risk for minorities that occurs when negative stereotypes associated with an individual's group status become relevant after perceived cues. ${ }^{5}$ Therefore, some students of color might avoid competitive specialties such as dermatology because of this internalized lack of confidence in their own abilities and performance thinking, "I'll never be good enough to match into dermatology." I have seen this discouraging perception when classmates doubt their own talent and achievements, which is a variation of imposter syndrome-when an individual doubts their abilities and may have an internal fear of eventually being exposed as a fraud.

After several publications received press coverage on the lack of diversity in dermatology applicant selection, ${ }^{3,6,7}$ I looked around at my interview group composed of 25 to 40 interviewees and on average saw 2 to 3 Black applicants around the room. We always found a way during the packed interview day to find time to introduce ourselves. I almost always left with a new friend who shared feelings of anxiety, uncertainty, hope, and gratefulness from being the few Black people in the room. Bootstrapping might have helped us to make it into medical school, pass shelf examinations, and even get a great Step 1 score. However, the addition of mentorship - or better yet, sponsorship - helped to get us an interview in this competitive field. The impact of mentorship has been especially true for research, which has shown that students often gravitate toward mentors who look like them. ${ }^{8}$ However, the reality is that many Black and Hispanic students may be at a disadvantage for finding mentors in this way given that there are less than $10 \%$ of dermatologists who identify as individuals with skin of color. During the process of applying to dermatology, my greatest advocates were ethnically and racially diverse. The proverb is that it takes a village to raise a child; this reality extends to the medical student's ability to thrive, not only in residency but also in the residency application process. My sponsors have been as different as their advice and perspectives, which helped me to think about the varied ways I viewed myself as an applicant and shaped what I looked for in residency.

\section{Final Thoughts}

Now that I have been a resident in the Department of Dermatology at the Warren Alpert Medical School of Brown University, I excitedly look for opportunities to mentor medical students and help create equity in the application process. Dermatology needs to increase the representation of minority applicants. Efforts to encourage minority medical students include joining the National Medical Association dermatology section through the Student National Medical Association, membership in the Skin of Color Society, getting involved with the Dermatology Interest Group at more medical schools, and awareness of medical student-friendly dermatology conferences. In addition, I was able to establish lifelong mentorship through the American Academy of Dermatology's Minority Diversity Mentorship Program. One important component is an enhanced effort to increase the number of financial scholarships for away rotations (postcoronavirus disease 2019 pandemic) or application expenses geared to help underrepresented minorities. To truly increase diversity in dermatology, perhaps we need more physicians and residents willing to encourage students of color that dermatology is achievable.

\section{REFERENCES}

1. Brunsma DL, Embrick DG, Shin JH. Graduate students of color: race, racism, and mentoring in the white waters of academia. Sociology of Race and Ethnicity. 2017;3:1-13.

2. Oyesanya T, Grossberg AL, Okoye GA. Increasing minority representation in the dermatology department: the Johns Hopkins experience. JAMA Dermatol. 2018;154:1133-1134.

3. Pandya AG, Alexis AF, Berger TG, et al. Increasing racial and ethnic diversity in dermatology: a call to action. J Am Acad Dermatol. 2016;74:584-587.

4. Current trends in medical education. American Association of Medical Colleges. Accessed January 20, 2021. http://www.aamc diversityfactsandfigures2016.org/report-section/section-3/

5. Spencer SJ, Logel C, Davies PG. Stereotype threat [published online September 10, 2015]. Annu Rev Psychol. 2016;67:415-437.

6. Granstein RD, Cornelius L, Shinkai K. Diversity in dermatology-a call for action. JAMA Dermatol. 2017;153:499-500.

7. Pritchett EN, Pandya AG, Ferguson NN, et al. Diversity in dermatology: roadmap for improvement. J Am Acad Dermatol. 2018;79:337-341.

8. Blake-Beard S, Bayne ML, Crosby FJ, et al. Matching by race and gender in mentoring relationships: keeping our eyes on the prize. J Social Issues. 2011;67:622-643. 